\title{
Piperine as an inhibitor of the MdeA efflux pump of Staphylococcus aureus
}

\author{
Correspondence \\ Inshad Ali Khan \\ iakhan@iiim.res.in or \\ inshad@rediffmail.com
}

Received 9 April 2011

Accepted 13 June 2011

\author{
Zahid Mehmood Mirza, ${ }^{1}$ Ashwani Kumar, ${ }^{2}$ Nitin Pal Kalia, ${ }^{2}$ Afzal Zargar $^{1}$ \\ and Inshad Ali Khan ${ }^{2}$
${ }^{1}$ Department of Biochemistry, Faculty of Science, University of Kashmir, Hazartbal, Srinagar 190 001, India
${ }^{2}$ Clinical Microbiology Division, Indian Institute of Integrative Medicine, Canal Road, Jammu Tawi 180001 , India

\begin{abstract}
Piperine, a trans-trans-isomer of 1-piperoyl-piperidine, was tested in combination with mupirocin for antimicrobial activity against Staphylococcus aureus strains including meticillin-resistant $S$. aureus. The combination markedly reduced the MIC of mupirocin and also lowered the mutation frequency. Enhanced accumulation and efflux of ethidium bromide from wild-type and mutant $\left(\mathrm{Mup}^{\mathrm{r}}-1\right)$ strains in the presence of piperine indicated that inhibition of efflux could be a possible mechanism of potentiation of mupirocin activity by piperine. The combination of piperine with mupirocin in a dermal infection model of mice showed better in vivo efficacy when compared with the commercially available formulation of $2 \%$ mupirocin.
\end{abstract}

\section{INTRODUCTION}

Meticillin-resistant Staphylococcus aureus (MRSA) is an emerging threat to public health in many parts of the world (Grundmann et al., 2006). It is one of the most commonly identified antibiotic-resistant pathogens responsible for nosocomial infections and accounts for approximately 40 $50 \%$ of infections in intensive care units (Diekema et al., 2001; Perl et al., 2002). Moreover, nasal carriage of this organism has been found to be the important factor in acquiring nosocomial infection in patients undergoing surgery and insertion of implant devices (Wertheim et al., 2005). A recent study showed a threefold increase in risk for non-surgical patients who were nasal carriers compared with non-carriers in acquiring a nosocomial $S$. aureus bacteraemia (Wertheim et al., 2004). The emergence of community-acquired MRSA has raised the alarm for better control of this organism.

Mupirocin (pseudomonic acid A) is one of four structurally related antibiotics, the others being pseudomonic acids B, C and D, isolated originally from Pseudomonas fluorescens. Mupirocin was introduced for the topical treatment of primary and secondary skin infections in 1985. This antibiotic inhibits RNA and protein synthesis by selective binding to the bacterial isoleucyl-tRNA synthetase and prevents the formation of isoleucyl-tRNA. However, the extensive use of mupirocin for eradication of MRSA colonization has resulted in the emergence of resistance in this organism. Due to emergence of resistance to

Abbreviations: MPC, mutation-prevention concentration; MRSA, meticillin-resistant Staphylococcus aureus. mupirocin, experts now recommend it as a prophylactic agent before surgery (Cookson, 1998). Interestingly, mupirocin resistance has been characterized as low level (MIC 8-256 $\mu \mathrm{g} \mathrm{ml}^{-1}$ ) and high level (MIC $\geqslant 512$ ) (Poupard, 1995). Low-level resistance is thought to result from spontaneous mutations in the chromosomal gene ileS-2 (тирA), whereas high-level resistance comes from the acquisition of a transferable plasmid containing the mирA gene, which encodes the divergent mupirocinresistant isoleucyl-tRNA synthetase (Schmitz et al., 2000). Furthermore, the use of mupirocin alone without systemic treatment in low-penetration situations, such as multiple or large wounds and in throat and rectal carriage, is also thought to encourage such mutations (Cookson, 1998). The process of efflux is carried out by membrane proteins called efflux pumps. These efflux pumps have evolved primarily in prokaryotic and eukaryotic cells to remove toxins from the interior of the cell. This protective function enables them to survive in hostile environments. In the case of mupirocin, a multidrug efflux transporter, MedA, has been found to be responsible for a 4-16-fold increase in its MIC (Huang et al., 2004). Inhibition of efflux pumps can significantly increase the clinical utility of existing antibiotics which are identified as the substrates of these pumps (Poole, 2004; Kumar et al., 2008). It is also noteworthy that the frequency of efflux-mediated resistance is often higher than the frequency of the resistance based on target alterations. In this way, the expression of efflux pumps has rendered many bacteria multidrugresistant (Lomovskaya \& Bostian, 2006). This has gained importance in the era of frequent multidrug resistance (Levy, 2002; Poole, 2004). Recently, we reported piperine 
and its analogues as potentiators of ciprofloxacin activity against $S$. aureus and found that piperine reduced the MIC of ciprofloxacin by up to eightfold in S. aureus 1199B (a NorA-hyperexpressing strain), indicating its role as a NorA inhibitor (Kumar et al., 2008).

In the present study, we evaluated piperine as a potentiator of the activity of mupirocin and its possible role as an inhibitor of the MdeA efflux pump of $S$. aureus.

\section{METHODS}

Bacteria. S. aureus ATCC 29213 was obtained from the American Type Culture Collection and used throughout the studies. S. aureus Mup $^{\mathrm{r}}-1$ was a laboratory-generated mupirocin-resistant mutant. The strains MRSA 33, MRSA 450 and MRSA 15187 were obtained from Ranbaxy Research Laboratories.

Antimicrobials and chemicals. Mupirocin powder ( $>98 \%$ pure) was a kind gift from Ochoa Laboratories. Ethidium bromide and piperine powder were purchased from Sigma-Aldrich.

Medium. All media were from Becton Dickinson. Mueller-Hinton broth (MHB) supplemented with calcium $\left(25 \mu \mathrm{g} \mathrm{ml}^{-1}\right)$ and magnesium $\left(12.5 \mu \mathrm{g} \mathrm{ml}^{-1}\right)$ was used for all susceptibility and killing curve experiments. Mueller-Hinton agar (MHA) was used for the mutant study. Tryptone soy agar (TSA) was used for performing colony counts.

In vitro combination studies. Combination studies were performed by a broth chequerboard method (Eliopoulus \& Moellering, 1996). A series of twofold dilutions of mupirocin in MHB ( $\mathrm{pH}$ 7.0) was tested in combination with twofold dilutions of piperine in 96-well microtitre plates. The final concentrations of mupirocin and piperine were $0.03-64$ and $0.8-50 \mu \mathrm{g} \mathrm{ml}^{-1}$, respectively. Bacterial inocula were prepared by adjusting the inoculum density of overnight cultures to a $0.5 \mathrm{McFarland}$ standard $\left(\sim 1.5 \times 10^{8}\right.$ c.f.u. $\left.\mathrm{ml}^{-1}\right)$ of Escherichia coli. These inocula were diluted $1: 100$ in sterile normal saline and $100 \mu \mathrm{l}$ of each diluted inoculum was dispensed in each well. The final bacterial inoculum in each well was equal to $5 \times 10^{5}$ c.f.u. $\mathrm{ml}^{-1}$. The plates were incubated at $37{ }^{\circ} \mathrm{C}$ for $24 \mathrm{~h}$.

Time-kill kinetics studies. Time-kill kinetics studies were carried out following the principles defined by the Clinical and Laboratory Standards Institute (CLSI, 1998). S. aureus ATCC 29213 was used as the test bacterium in this study. Mupirocin was tested alone at concentrations of 0.125 and $0.25 \mu \mathrm{g} \mathrm{ml}^{-1}$, as well as in combination with piperine at a concentration of $25 \mu \mathrm{g} \mathrm{ml}^{-1}$. A bacterial inoculum of $5 \times 10^{6}$ c.f.u. $\mathrm{ml}^{-1}$ was added to $20 \mathrm{ml} \mathrm{MHB}$ and the inoculated flasks were incubated at $37{ }^{\circ} \mathrm{C}$ with shaking. The number of c.f.u. was determined on TSA using a serial dilution method at intervals of $2 \mathrm{~h}$ up to $24 \mathrm{~h}$. Because of the initial $1: 10$ dilution of all samples (resulting in sub-MIC concentrations of mupirocin), no antibiotic carryover was observed. The plates were incubated at $37{ }^{\circ} \mathrm{C}$ for $18-24 \mathrm{~h}$.

Selection of resistant mutants in vitro. First-step mutants of S. aureus ATCC 29213 were selected as described previously (Drugeon et al., 1999). A bacterial suspension containing $10^{9}$ c.f.u. in $100 \mu \mathrm{l}$ was plated on MHA containing mupirocin at different concentrations varying from 0.5 to $2 \mu \mathrm{g} \mathrm{ml}^{-1}$, individually and in combination with piperine at 25 and $50 \mu \mathrm{g} \mathrm{ml}^{-1}$. Mutation frequencies were calculated by dividing the total number of colonies appearing after $48 \mathrm{~h}$ of incubation at $37^{\circ} \mathrm{C}$ on the drug-containing plate by the total number of c.f.u. plated.
Selection and susceptibility of mupirocin-resistant mutants of S. aureus. Mupirocin-resistant mutants were selected by plating $10^{8}$ c.f.u. S. aureus ATCC 29213 on an MHA plate containing $0.5 \mu \mathrm{g}$ mupirocin $\mathrm{ml}^{-1}(2 \times \mathrm{MIC})$. Ten colonies were randomly picked and individually passaged on MHA medium with increasing concentrations of mupirocin (up to $256 \mu \mathrm{g} \mathrm{ml}^{-1}$ ). The susceptibilities of these mutants to mupirocin (in the presence or absence of $25 \mu \mathrm{g}$ reserpine or piperine $\mathrm{ml}^{-1}$ ) were determined by an agar dilution method (CLSI, 2008). One of the mupirocin-resistant mutants showing an MIC of $256 \mu \mathrm{g} \mathrm{ml}^{-1}$ was designated Mup ${ }^{\mathrm{r}}-1$. This mutant and S. aureus ATCC 29213 were used to check the restoration of the MIC of mupirocin and ethidium bromide by piperine using the broth microdilution method. Reserpine (a known efflux pump inhibitor) at $25 \mu \mathrm{g} \mathrm{ml}^{-1}$ was used as a control in this study.

Effect of piperine on the accumulation and efflux of ethidium bromide. Measurement of the level of ethidium bromide accumulation and efflux in wild-type S. aureus 29213 and the mutant strain Mup $^{\mathrm{r}}-1$ was based on a previously described method (Brenwald et al., 1998). Briefly, for measurement of the level of accumulation, bacterial strains were grown overnight on TSA. Bacterial suspensions were prepared at an $\mathrm{OD}_{550}$ of 0.2 in uptake buffer $\left[110 \mathrm{mM} \mathrm{NaCl}, 7 \mathrm{mM} \mathrm{KCl}, 50 \mathrm{mM} \quad \mathrm{NH}_{4} \mathrm{Cl}, 0.4 \mathrm{mM}\right.$ $\mathrm{Na}_{2} \mathrm{HPO}_{4}, 52 \mathrm{mM}$ Tris base, $0.2 \%(\mathrm{w} / \mathrm{v})$ glucose, adjusted to $\mathrm{pH} 7.5$ with $\mathrm{HCl}$ ] and exposed to ethidium bromide at a concentration of $2 \mu \mathrm{g} \mathrm{ml}^{-1}$. The increase in fluorescence as ethidium bromide entered the cells was recorded with a Perkin-Elmer model LS50 spectrofluorometer (excitation $\lambda, 530 \mathrm{~nm}$; emission $\lambda$, $600 \mathrm{~nm}$ ) at $30{ }^{\circ} \mathrm{C}$. The effect of piperine on the level of accumulation was determined in a similar way, except that piperine was added to the uptake buffer at a concentration of $25 \mu \mathrm{g} \mathrm{m}^{-1}$. For determining ethidium bromide efflux, bacterial suspensions were prepared as described above and exposed to ethidium bromide $(2 \mu \mathrm{g}$ $\left.\mathrm{ml}^{-1}\right)$ in the presence of piperine $\left(25 \mu \mathrm{g} \mathrm{ml}^{-1}\right)$ for $30 \mathrm{~min}$ at $37{ }^{\circ} \mathrm{C}$. The cells were pelleted by centrifugation and resuspended in fresh uptake buffer. The efflux of ethidium bromide from the cells was measured as a decrease in fluorescence.

PCR amplification and sequencing of the promoter region of the $\boldsymbol{m d e} \boldsymbol{A}$ gene of $\boldsymbol{S}$. aureus Mup ${ }^{r}-\mathbf{1}$. DNA was isolated from the cell pellet obtained from an overnight culture of $S$. aureus Mup $^{\mathrm{r}}-1$. The DNA was dissolved in sterile DNase- and RNase-free water and quantified using a NanoDrop spectrometer (Thermo Fisher Scientific). Primers were designed using Primer3 software (Rozen \& Skaletsky, 2000) and were purchased from Sigma. The primers used for $m d e A$ amplification were 5'-TTCATCTCTATCCCTCCTTG-3' (forward) and 5'-CTTCGACATTTAAAGCTTCCC-3' (reverse) with a product size of $186 \mathrm{bp}$. PCR amplification was carried out in a $20 \mu \mathrm{l}$ reaction mixture containing $1 \times$ PCR buffer (MBI Fermentas), $0.20 \mathrm{mM}$ dNTPs, 5 pmol each primer, $1.5 \mathrm{U}$ DNA Taq polymerase (MBI Fermentas) and $\sim 50 \mathrm{pmol}$ genomic DNA isolated from $S$. aureus $\mathrm{Mup}^{\mathrm{r}}-1$. The thermal cycling parameters were: $5 \mathrm{~min}$ at $94{ }^{\circ} \mathrm{C}, 35$ cycles of $1 \mathrm{~min}$ at $94{ }^{\circ} \mathrm{C}, 45 \mathrm{~s}$ at $53{ }^{\circ} \mathrm{C}$ and $1 \mathrm{~min}$ at $72{ }^{\circ} \mathrm{C}$, and a final extension of $10 \mathrm{~min}$ at $72{ }^{\circ} \mathrm{C}$. The PCR product was purified using a PCR purification kit (Qiagen) and subjected to sequence analysis by the Big Dye terminator cycle sequencing method using an ABI PRISM 377XL sequencer (Applied Biosystems).

In vivo efficacy of the combination. The in vivo efficacy of the combination was tested in a mouse model of infection. This study was approved by the Institutional Animal Ethics Committee (IAEC study no. SSP-0415, August 2009). A dermal infection model was developed on 2-3-week-old female Swiss albino mice weighing 20-22 g using MRSA 15187 as the infectious organism. The complete back side of 
Table 1. MIC of mupirocin in combination with piperine

\begin{tabular}{|c|c|c|c|c|c|}
\hline \multirow[t]{3}{*}{ S. aureus strain } & \multirow[t]{3}{*}{ Piperine MIC $\left(\mu \mathrm{g} \mathrm{ml}^{-1}\right)$} & \multicolumn{4}{|c|}{ Mupirocin MIC $\left(\mu \mathrm{g} \mathrm{ml}^{-1}\right)$} \\
\hline & & \multirow[t]{2}{*}{ Without piperine } & \multicolumn{3}{|c|}{ With piperine $\left(\mu \mathrm{g} \mathrm{ml}^{-1}\right)$} \\
\hline & & & 50 & 25 & 12.5 \\
\hline ATCC 29213 & $>100$ & 0.25 & 0.06 & 0.12 & 0.12 \\
\hline Mup $^{r}-1$ & $>100$ & 256 & 64 & 64 & 128 \\
\hline MRSA 33 & $>100$ & 0.25 & 0.12 & 0.12 & 0.25 \\
\hline MRSA 450 & $>100$ & 0.25 & 0.12 & 0.25 & 0.25 \\
\hline MRSA 15187 & $>100$ & 0.25 & 0.06 & 0.12 & 0.25 \\
\hline
\end{tabular}

the anaesthetized mouse was cleaned by removing hair and a bloodoozing patch of $1 \mathrm{~cm}^{2}$ was created by abrasion with sandpaper. A sterile cotton swab dipped in inoculum adjusted to a $0.5 \mathrm{McF}$ arland standard (prepared from an overnight culture) was applied to the abraded area and left for $24 \mathrm{~h}$ to establish infection. Treatment was started at $24 \mathrm{~h}$ post-infection and each group of five mice was treated three times a day for 5 consecutive days with $2 \%$ and $0.5 \%$ $(\mathrm{w} / \mathrm{v})$ mupirocin alone, and with $0.5 \%(\mathrm{w} / \mathrm{v})$ mupirocin in combination with $0.5 \%$ and $0.25 \%(\mathrm{w} / \mathrm{v})$ piperine. Both mupirocin and mupirocin combined with piperine were formulated in polyethylene glycol 400 (Rankem). Formulations were applied over the infected area with the help of a sterile cotton swab. A group of infected mice treated with placebo (polyethylene glycol) was used as the untreated control. The mice were sacrificed humanely by $\mathrm{CO}_{2}$ asphyxiation $24 \mathrm{~h}$ after the last treatment was applied. The infected patch was aseptically dissected and homogenized in $1 \mathrm{ml}$ normal sterile saline. Serial tenfold dilutions of the homogenates were plated in triplicate onto MHA supplemented with $2 \mu \mathrm{g}$ ciprofloxacin $\mathrm{ml}^{-1}$. The plates were incubated overnight at $37{ }^{\circ} \mathrm{C}$ and bacterial colonies were enumerated manually to calculate the number of c.f.u. per infected skin patch.

Statistical analysis. All experiments were repeated two to three times with two replicates for each condition tested and similar results were obtained on all occasions. Data were expressed as means \pm SD and statistical analysis was carried out using Excel 2003 (Microsoft).

\section{RESULTS}

\section{Combination studies}

The results of the chequerboard combination studies performed at $\mathrm{pH} 7.0$ are shown in Table 1. A fourfold reduction in the MIC of mupirocin from 0.25 to $0.06 \mu \mathrm{g}$ $\mathrm{ml}^{-1}$ for S. aureus ATCC 29213 was observed when piperine was tested at $50 \mu \mathrm{g} \mathrm{ml}^{-1}$. The same concentration of piperine was also found to be effective in reducing the MIC of the three MRSA strains tested in this study. This reduction in MIC was most prominent for S. aureus Mup $^{\mathrm{r}}-1$, which exhibited a fourfold reduction in the MIC of mupirocin in presence of $25 \mu \mathrm{g}$ piperine $\mathrm{ml}^{-1}$.

\section{Time-kill studies}

Kill curves were constructed by plotting $\log _{10}$ c.f.u. $\mathrm{ml}^{-1}$ against time over $24 \mathrm{~h}$ (Fig. 1). The growth curve of piperine alone at $25 \mu \mathrm{g} \mathrm{ml}^{-1}$ was similar to the growth control curve, indicating that piperine alone was not associated with any antibacterial activity. Mupirocin alone showed bacteriostatic activity at its MIC $\left(0.25 \mu \mathrm{g} \mathrm{ml}^{-1}\right)$ and sub-MIC $\left(0.12 \mu \mathrm{g} \mathrm{ml}^{-1}\right)$, whereas in combination with

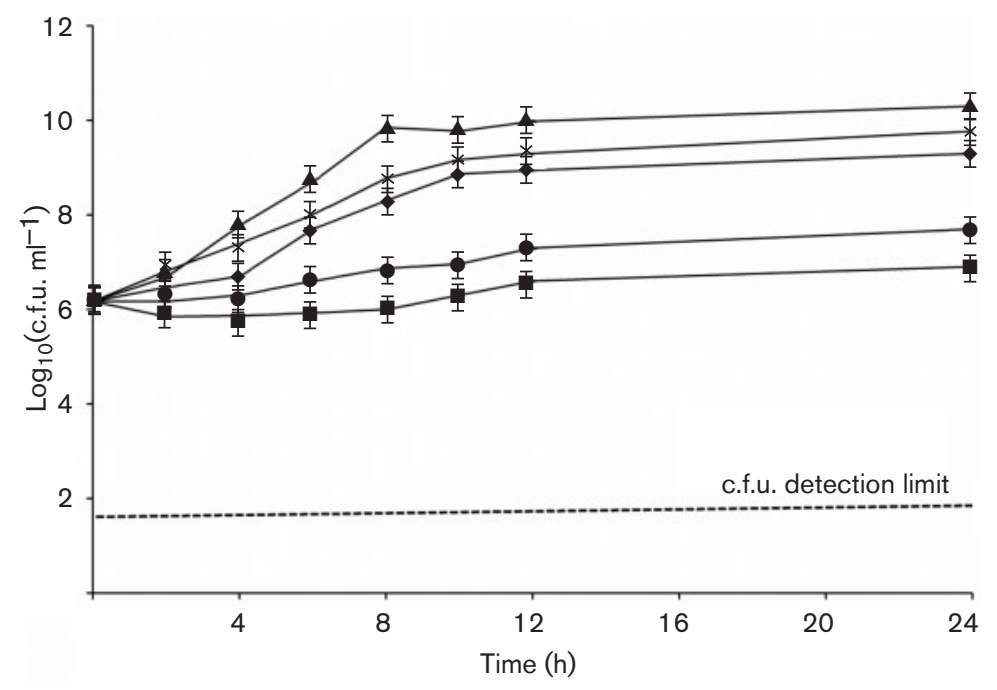

Fig. 1. Time-kill kinetics curves of $S$. aureus for mupirocin with and without piperine over a period of $24 \mathrm{~h}$ in MHB. The experiment was conducted a minimum of three times and the results were normalized. Results are shown as means $\pm \mathrm{SD}$. $\bullet$, Mupirocin $\left(0.25 \mu \mathrm{g} \mathrm{ml}^{-1}\right)$; $\checkmark$ mupirocin $\left(0.12 \mu \mathrm{g} \mathrm{ml}^{-1}\right) ; \times$, piperine $(25$ $\left.\mu \mathrm{g} \mathrm{ml}{ }^{-1}\right) ; \boldsymbol{\square}$, mupirocin $\left(0.12 \mu \mathrm{g} \mathrm{ml}^{-1}\right)$ + piperine $\left(25 \mu \mathrm{g} \mathrm{ml}^{-1}\right) ; \boldsymbol{\Delta}$, control. 
Table 2. Frequency of mutation in S. aureus ATCC 29213 with mupirocin in the presence and absence of piperine

\begin{tabular}{|c|c|c|c|}
\hline \multirow[t]{2}{*}{ Piperine $\left(\mu \mathrm{g} \mathrm{ml}^{-1}\right)$} & \multicolumn{3}{|c|}{ Mutation frequency with mupirocin at: } \\
\hline & $2 \times \operatorname{MIC}\left(0.5 \mu \mathrm{g} \mathrm{ml}^{-1}\right)$ & $4 \times \operatorname{MIC}\left(1 \mu \mathrm{g} \mathrm{ml}^{-1}\right)$ & $8 \times \operatorname{MIC}\left(2 \mu \mathrm{g} \mathrm{ml}^{-1}\right)$ \\
\hline 25 & $1.6 \times 10^{-8}$ & $<10^{-9}$ & $<10^{-9}$ \\
\hline 50 & $<10^{-9}$ & $<10^{-9}$ & $<10^{-9}$ \\
\hline
\end{tabular}

piperine at $25 \mu \mathrm{g} \mathrm{m} \mathrm{ml}^{-1}$, the sub-MIC concentration of mupirocin exhibited superior inhibitory activity compared with the MIC concentration of mupirocin alone. The combination further reduced the c.f.u. by a further $1.5 \operatorname{logs}$ with respect to the starting inocula and maintained the bacteriostatic regime up to $24 \mathrm{~h}$.

\section{Effect on mutation frequency}

Mutation frequency was calculated by dividing the total number of colonies appearing on the drug-containing plate by the total number of c.f.u. plated (Table 2). There was a reduction in the frequency of mutants with the increase in concentration of mupirocin until there was no mutant selected at $2 \mu \mathrm{g} \mathrm{ml}^{-1}(8 \times \mathrm{MIC})$. This concentration of mupirocin was defined as the mutation-prevention concentration (MPC). Interestingly, mupirocin in combination with piperine significantly lowered the mutation frequency and there was a $>2 \log$ reduction in mutation frequency at $0.5 \mu \mathrm{g}$ mupirocin $\mathrm{ml}^{-1}(2 \times \mathrm{MIC})$ in combination with $25 \mu \mathrm{g}$ piperine $\mathrm{ml}^{-1}$ when compared with the same concentration of mupirocin alone. In addition, at $1 \mu \mathrm{g}$ mupirocin $\mathrm{ml}^{-1}(4 \times \mathrm{MIC})$ in combination with $25 \mu \mathrm{g}$ piperine $\mathrm{ml}^{-1}$, no mutants were selected, thereby reducing the MPC of mupirocin from 2 to $1 \mu \mathrm{g}$ $\mathrm{ml}^{-1}$. When the concentration of piperine was further increased to $50 \mu \mathrm{g} \mathrm{ml}^{-1}$, there no mutants were detected, even at $0.5 \mu \mathrm{g}$ mupirocin $\mathrm{ml}^{-1}$.

\section{Susceptibilities of selected mutants}

A total of ten resistant mutants showing an MIC of $\geqslant 128 \mu \mathrm{g}$ mupirocin $\mathrm{ml}^{-1}$ were selected (data not shown). The MIC of ethidium bromide was also determined for these mutants. Table 3 shows the MIC results for mupirocin and ethidium bromide of wild-type $S$. aureus ATCC 29213 and one of the ten mutants, Mup ${ }^{r}-1$. The reduction of the MICs of mupirocin and ethidium bromide by piperine was studied using reserpine, which is a known efflux pump blocker and served as a control. Mup ${ }^{\mathrm{r}}-1$ showed a 2048-fold increase in the MIC of mupirocin and a twofold increase in the MIC of ethidium bromide when compared with the wild-type. The MICs of mupirocin and ethidium bromide for both isolates (wild-type and Mup $^{\mathrm{r}}-1$ mutant) were reduced by piperine and reserpine. As efflux is the only known mechanism for ethidium bromide resistance, the reduction of its MIC for the Mup $^{r}-1$ mutant to a value similar to that of the wild-type indicated that piperine has a role as an efflux pump inhibitor.

\section{Accumulation and efflux of ethidium bromide}

Figs 2 and 3 compare the level of accumulation and efflux, respectively, of ethidium bromide in the wild-type S. aureus ATCC 29213 and mutant $\mathrm{Mup}^{\mathrm{r}}-1$. The initial rate of accumulation of ethidium bromide in the mutant was significantly lower than in the wild-type. However, with the addition of piperine $\left(25 \mu \mathrm{g} \mathrm{ml}^{-1}\right)$ after $30 \mathrm{~min}$, this difference in accumulation was significantly reduced and there was increased accumulation of ethidium bromide in both strains (Fig. 2). The rate of ethidium bromide loss from Mup $^{r}-1$ increased significantly compared with that of the wild-type strain. Again, addition of piperine dramatically decreased the efflux rate of mupirocin in Mup $^{r}-1$. Similar results were obtained when reserpine was used as a known efflux pump blocker (data not shown).

\section{Sequence analysis of the promoter region of the mdeA gene}

The sequence of the promoter region of the $m d e A$ gene of S. aureus $\mathrm{Mup}^{\mathrm{r}}-1$ was compared with that of a published $S$. aureus mdeA gene sequence ( $S$. aureus Mu50, GenBank

Table 3. Susceptibility of $S$. aureus ATCC 29213 and its mupirocin-selected mutant, Mup ${ }^{r}-1$, in the presence of ethidium bromide or mupirocin and the efflux pump inhibitors piperine and reserpine at a concentration of $25 \mu \mathrm{g} \mathrm{ml}^{-1}$

\begin{tabular}{|c|c|c|}
\hline \multirow[t]{2}{*}{$\operatorname{Compound}(\mathrm{s})\left(\mu \mathrm{g} \mathrm{ml}^{-1}\right)$} & \multicolumn{2}{|c|}{$\operatorname{MIC}\left(\mu \mathrm{g} \mathrm{ml}^{-1}\right)$} \\
\hline & $\begin{array}{c}\text { S. aureus } \\
\text { ATCC } 29213\end{array}$ & $\operatorname{Mup}^{\mathrm{r}}-1$ \\
\hline Ethidium bromide & 4 & 8 \\
\hline $\begin{array}{l}\text { Ethidium bromide }+ \text { reserpine } \\
\left(25 \mu \mathrm{g} \mathrm{ml}^{-1}\right)\end{array}$ & 2 & 2 \\
\hline $\begin{array}{l}\text { Ethidium bromide }+ \text { piperine } \\
\left(25 \mu \mathrm{g} \mathrm{m}^{-1}\right)\end{array}$ & 1 & 2 \\
\hline Mupirocin & 0.125 & 256 \\
\hline $\begin{array}{l}\text { Mupirocin + reserpine } \\
\left(25 \mu \mathrm{g} \mathrm{ml}^{-1}\right)\end{array}$ & 0.06 & 128 \\
\hline $\begin{array}{l}\text { Mupirocin + piperine } \\
\left(25 \mu \mathrm{g} \mathrm{ml}^{-1}\right)\end{array}$ & 0.06 & 64 \\
\hline
\end{tabular}




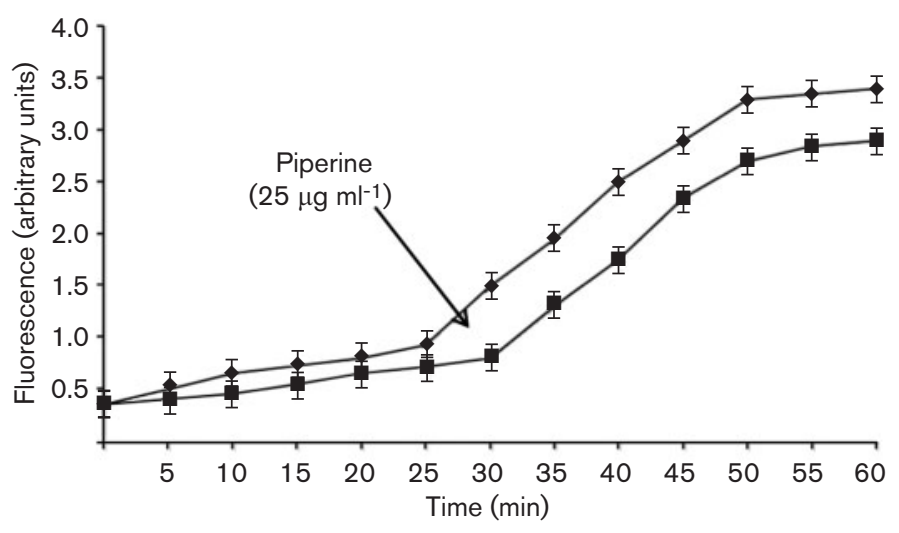

Fig. 2. Accumulation of ethidium bromide in wild-type S. aureus ATCC $29213(\boldsymbol{})$ and mutant Mup ${ }^{r}-1(\boldsymbol{\square})$ alone or in combination with $25 \mu \mathrm{g}$ piperine $\mathrm{ml}^{-1}$, added after $30 \mathrm{~min}$.

accession no. NC_002758). Sequence comparison revealed single base substitution point mutations 54 bp upstream of the translation initiation codon $(\mathrm{C} \rightarrow \mathrm{A})$ in the -10 region sequence and in the -35 region sequence from GTGCTA to TTGCTA $(\mathrm{G} \longrightarrow \mathrm{T})$ (Fig. 4).

\section{Effect of piperine on the in vivo potency of mupirocin}

The in vivo effect of mupirocin and piperine was evaluated by observing the physical appearance of the wound. Quantitative analysis of the wound was performed by estimating the bacterial load in a $1 \mathrm{~cm}^{2}$ skin patch. The bacterial c.f.u. load in the skin patch placebo-treated control group was $1.7 \times 10^{7}$ (Table 4 ). Mupirocin at $2 \%$ $(\mathrm{w} / \mathrm{v})$ concentration was able to sterilize only two out of five mice, with a mean c.f.u. of $1.8 \times 10^{4}$ in the three infected mice. A combination of $0.5 \%(\mathrm{w} / \mathrm{v})$ mupirocin with $0.5 \%(\mathrm{w} / \mathrm{v})$ piperine was found to be the most effective formulation in sterilizing the infected skin patch. Out of five mice treated with this formulation, four were cured completely. A c.f.u. count of $2.5 \times 10^{3}$ was recovered from one infected mouse in this group. The other combination of $0.5 \%(\mathrm{w} / \mathrm{v})$ mupirocin with $0.25 \%(\mathrm{w} / \mathrm{v})$ piperine was inferior to the previous combination, exhibiting sterilization in three of the five mice, with a mean c.f.u. of $4.0 \times 10^{4}$ in two infected mice. The two latter combinations containing $0.5 \%$ mupirocin exhibited a better curing efficacy than $2 \%$ mupirocin, which is available commercially as an ointment or cream (GlaxoSmithKline). A further reduction in the mupirocin concentration to $0.25 \%(\mathrm{w} / \mathrm{v})$ did not yield the desired therapeutic effect (not shown).

\section{DISCUSSION}

Antibiotic efflux was first discovered in 1980, when it was recognized as a mechanism for tetracycline resistance in enterobacteria (Levy, 1992). Since then, it has been shown that almost all antibiotics are subject to resistance by efflux in Gram-positive and Gram-negative bacteria (Nikaido, 2001; Li \& Nikaido, 2004). The findings revealed that upregulation of efflux systems through physiological induction and spontaneous mutation can significantly lower the intracellular concentration of many such agents, causing an impact on their clinical efficacy.

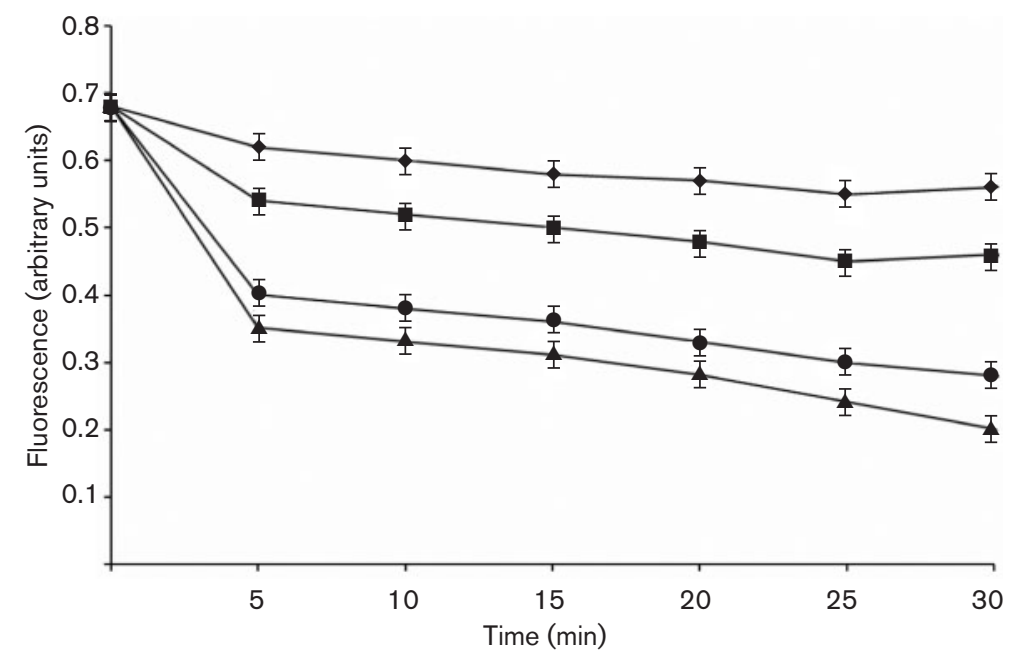

Fig. 3. Efflux of ethidium bromide in wild-type S. aureus ATCC 29213 and Mup ${ }^{r}-1$ alone or in combination with $25 \mu \mathrm{g}$ piperine $\mathrm{ml}^{-1}$.,$S$. aureus ATCC 29213; $\mathbf{\square}, S$. aureus ATCC 29213 + piperine $\left(25 \mu \mathrm{g} \mathrm{ml}^{-1}\right) ; \boldsymbol{\Delta}, \mathrm{Mup}^{\mathrm{r}}-1$; $\checkmark$ Mup ${ }^{\mathrm{r}}-1+$ piperine $\left(25 \mu \mathrm{g} \mathrm{ml}^{-1}\right)$. 


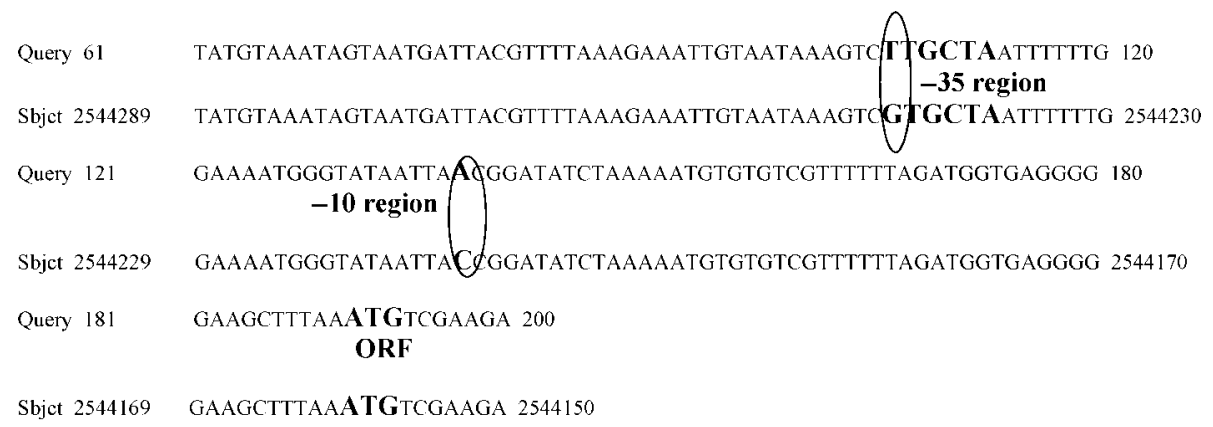

Fig. 4. Sequence analysis of the promoter region of the $m d e A$ gene of the Mup ${ }^{r}-1$ mupirocin mutant of $S$. aureus compared with the sequence of S. aureus Mu50 (GenBank accession no. NC_002758). Base substitutions are indicated within the -35 and -10 promoter elements. The start of the open reading frame (ORF) is indicated.

The approach of identifying molecules that can interfere with the process of efflux to enhance the potential of existing antibiotics has become the process of choice to tackle antibiotic resistance and explore genomic-driven new lead molecules (Poole \& Lomovskaya, 2006). Such compounds can significantly improve antibiotic efficacy by raising physiological levels of an antibiotic and act synergistically by reducing bacterial efflux. In this regard, preliminary success has already been achieved in determining efflux pump inhibitors of various efflux pumps of Gram-positive and Gram-negative bacteria.

The first report of piperine as an inhibitor of the NorA efflux pump in S. aureus came from our group (Khan et al., 2006). Recently, we have reported that it is also an inhibitor of Rv1258c, a putative multidrug efflux pump of Mycobacterium tuberculosis (Sharma et al., 2010). To investigate further its broad-spectrum efflux pump inhibitory activity, in the present study we tested piperine for potentiation of the activity of mupirocin. Piperine exhibited a two- to fourfold reduction in the MIC of mupirocin for S. aureus ATCC 29213 and MRSA isolates. The relative probability of the mupirocin and piperine combination to select resistant mutants was found to be significantly lower in comparison with mupirocin alone. The MPC has been proposed as a new measurement of antibiotic potency by which the ability to restrict selection of resistant mutants is evaluated. It was observed that there was an increase in the MIC of ethidium bromide in $S$. aureus Mup $^{\mathrm{r}}-1$ and there was enhanced accumulation of ethidium bromide in these cells. Piperine reversed the MIC of ethidium bromide and inhibited the efflux from these mutant cells pre-loaded with ethidium bromide, thus indicating inhibition of the efflux mechanism.

Overexpression of MdeA confers resistance on S. aureus to a range of quarternary ammonium compounds and antibiotics including mupirocin. It is a $52 \mathrm{kDa}$ protein with 14 predicted transmembrane segments (Huang et al., 2004). Sequencing analysis of the promoter region of $S$. aureus Mup $^{\mathrm{r}}-1$ revealed single base substitution point mutations of $\mathrm{C} \rightarrow \mathrm{A}$ between the initiation codon and the -10 region, and $\mathrm{G} \longrightarrow \mathrm{T}$ in the -35 region. Similar mutations have also been reported by Huang et al. (2004) in a mutant which showed a 320 -fold increase in the transcription of mdeA.

The in vitro potentiation of mupirocin by piperine was successfully translated into improved in vivo efficacy shown by the formulation containing a combination of mupirocin and piperine in a mouse skin infection model. The combination of $0.5 \%$ mupirocin and $0.5 \%$ piperine exhibited maximum sterilization effect at one-quarter of the dose of the commercially available $2 \%$ mupirocin formulation (Table 4). Piperine is pharmacologically safe and also features in the US Food and Drug Administration list of 'Generally Regarded as Safe' or GRAS compounds. Therefore, a topical formulation of piperine and mupirocin should not have any toxicity concerns and may prove to be useful in nasal decolonization therapy and the treatment of dermatological infections.

Table 4. In vivo efficacy of mupirocin alone or in combination with piperine against MRSA 15187 in a Swiss albino mouse dermal infection model

\begin{tabular}{|lcc|}
\hline Treatment group & Growth/total no. mice & Mean $\log _{\mathbf{1 0}}$ c.f.u. recovered per infected skin patch \\
\hline Control & $5 / 5$ & $7.2304 \pm 0.16$ \\
$2 \%$ Mupirocin & $3 / 5$ & $4.2552 \pm 0.19$ \\
$0.5 \%$ Mupirocin & $4 / 5$ & $5.3979 \pm 0.18$ \\
$0.5 \%$ Mupirocin $+0.5 \%$ piperine & $1 / 5$ & $3.3979 \pm 0.25$ \\
$0.5 \%$ Mupirocin $+0.25 \%$ piperine & $2 / 5$ & $4.6020 \pm 0.24$ \\
\hline
\end{tabular}




\section{ACKNOWLEDGEMENTS}

The authors thank the Director of the Indian Institute of Integrative Medicine, India, for his sustained interest and encouragement. We are also thankful to Ranbaxy Research Laboratories for providing the MRSA isolates.

\section{REFERENCES}

Brenwald, N. P., Gill, M. J. \& Wise, R. (1998). Prevalence of a putative efflux mechanism among fluoroquinolone-resistant clinical isolates of Streptococcus pneumoniae. Antimicrob Agents Chemother 42, 20322035.

CLSI (1998). Methods for Determining Bactericidal Activity of Antimicrobial Agents; Approved Standard. M26-A. Wayne, PA: Clinical and Laboratory Standards Institute.

CLSI (2008). Methods for Dilution Antimicrobial Susceptibility Tests for Bacteria that Grow Aerobically; Approved Standard. M7-A8. Wayne, PA: Clinical and Laboratory Standards Institute.

Cookson, B. D. (1998). The emergence of mupirocin resistance: a challenge to infection control and antibiotic prescribing practice. J Antimicrob Chemother 41, 11-18.

Diekema, D. J., Pfaller, M. A., Schmitz, F. J., Smayevsky, J., Bell, J., Jones, R. N., Beach, M. \& the SENTRY Partcipants Group (2001). Survey of infections due to Staphylococcus species: frequency of occurrence and antimicrobial susceptibility of isolates collected in the United States, Canada, Latin America, Europe, and the Western Pacific region for the SENTRY Antimicrobial Surveillance Program, 1997-1999. Clin Infect Dis 32 (Suppl. 2), S114-S132.

Drugeon, H. B., Juvin, M. E. \& Bryskier, A. (1999). Relative potential for selection of fluoroquinolone-resistant Streptococcus pneumoniae strains by levofloxacin: comparison with ciprofloxacin, sparfloxacin and ofloxacin. J Antimicrob Chemother 43 (Suppl. C), 55-59.

Eliopoulus, G. M. \& Moellering, R. C. J. (1996). Antimicrobial combinations. In Antibiotics in Laboratory Medicine, 4th edn, pp. 330396. Edited by V. Lorian. Baltimore, MD: Williams \& Wilkins.

Grundmann, H., Aires-de-Sousa, M., Boyce, J. \& Tiemersma, E. (2006). Emergence and resurgence of meticillin-resistant Staphylococcus aureus as a public-health threat. Lancet 368, 874-885.

Huang, J. O., O'Toole, P. W., Shen, W., Amrine-Madsen, H., Jiang, X., Lobo, N., Palmer, L. M., Voelker, L., Fan, F. \& other authors (2004). Novel chromosomally encoded multidrug efflux transporter MdeA in Staphylococcus aureus. Antimicrob Agents Chemother 48, 909-917.

Khan, I. A., Mirza, Z. M., Kumar, A., Verma, V. \& Qazi, G. N. (2006). Piperine, a phytochemical potentiator of ciprofloxacin against Staphylococcus aureus. Antimicrob Agents Chemother 50, 810-812.
Kumar, A., Khan, I. A., Koul, S., Koul, J. L., Taneja, S. C., Ali, I., Ali, F., Sharma, S., Mirza, Z. M. \& other authors (2008). Novel structural analogues of piperine as inhibitors of the NorA efflux pump of Staphylococcus aureus. J Antimicrob Chemother 61, 1270-1276.

Levy, S. B. (1992). Active efflux mechanisms for antimicrobial resistance. Antimicrob Agents Chemother 36, 695-703.

Levy, S. B. (2002). Active efflux, a common mechanism for biocide and antibiotic resistance. J Appl Microbiol 92 (Suppl.), 65S-71S.

Li, X. Z. \& Nikaido, H. (2004). Efflux-mediated drug resistance in bacteria. Drugs 64, 159-204.

Lomovskaya, O. \& Bostian, K. A. (2006). Practical applications and feasibility of efflux pump inhibitors in the clinic - a vision for applied use. Biochem Pharmacol 71, 910-918.

Nikaido, H. (2001). Preventing drug access to targets: cell surface permeability barriers and active efflux in bacteria. Semin Cell Dev Biol 12, 215-223.

Perl, T. M., Cullen, J. J., Wenzel, R. P., Zimmerman, M. B., Pfaller, M. A., Sheppard, D., Twombley, J., French, P. P., Herwaldt, L. A. \& the Mupirocin and the Risk of Staphylococcus aureus Study Team (2002). Intranasal mupirocin to prevent postoperative Staphylococcus aureus infection. $N$ Engl J Med 346, 1871-1877.

Poole, K. (2004). Efflux-mediated multiresistance in Gram-negative bacteria. Clin Microbiol Infect 10, 12-26.

Poole, K. \& Lomovskaya, O. (2006). Can efflux inhibitors really counter resistance? Drug Discov Today Ther Strateg 3, 145-152.

Poupard, J. A. (1995). Update on mupirocin resistance. J Chemother 7 (Suppl. 3), 71-74.

Rozen, S. \& Skaletsky, H. (2000). Primer3 on the WWW for general users and for biologist programmers. Methods Mol Biol 132, 365-386.

Schmitz, F. J., Fluit, A. C., Lindenlauf, E., Scheuring, S. \& Köhrer, K. (2000). Molecular analyses of possible mechanisms coding for lowlevel mupirocin resistance in clinical Staphylococcus aureus isolates. Eur J Clin Microbiol Infect Dis 19, 649-650.

Sharma, S., Kumar, M., Sharma, S., Nargotra, A., Koul, S. \& Khan, I. A. (2010). Piperine as an inhibitor of Rv1258c, a putative multidrug efflux pump of Mycobacterium tuberculosis. J Antimicrob Chemother 65, 1694-1701.

Wertheim, H. F. L., Vos, M. C., Ott, A., van Belkum, A., Voss, A., Kluytmans, J. A., van Keulen, P. H., Vandenbroucke-Grauls, C. M., Meester, M. H. \& Verbrugh, H. A. (2004). Risk and outcome of nosocomial Staphylococcus aureus bacteraemia in nasal carriers versus non-carriers. Lancet 364, 703-705.

Wertheim, H. F. L., Melles, D. C., Vos, M. C., van Leeuwen, W., van Belkum, A., Verbrugh, H. A. \& Nouwen, J. L. (2005). The role of nasal carriage in Staphylococcus aureus infections. Lancet Infect Dis 5, $751-762$. 